\title{
High energy impact on woven laminates
}

\author{
J. López-Puente, R. Zaera and C. Navarro \\ Department of Continuum Mechanics and Structural Analysis, Carlos III University of Madrid, \\ Avda. de la Universidad 30, 28911 Leganés, Madrid, Spain
}

\begin{abstract}
The influence of high velocity impacts on CFRPs was studied by launching Spherical steel masses, at velocities from $60 \mathrm{~m} / \mathrm{s}$ to $550 \mathrm{~m} / \mathrm{s}$, against carbon fiber/epoxy woven laminates. The extension of the damage induced in the laminate was measured by C-Scan. Finite element numerical simulation of the impact test used a failure model based on the Chang-Chang model. A comparison was made of the damaged areas resulting from non-destructive inspection of the specimens and those predicted by mumerical simulation. To conclude the analysis, an analytical model developed by Cantwell-Morton was used to calculate the residual velucity of the projectile after perforation. The residual velocities predicted by numerical and by analytical models, were also compared.
\end{abstract}

\section{INTRODUCTION}

Fiber reinforced plastic (FRP) composites are commonly used for low weight structures; many structural components are made with this kind of material in the aeronautic and aerospace industries. The lower cost of their manufacture in recent years has led to their use in other applications such as ship hulls, in high-speed trains or in the automotive industry. Among FRPs, carbon fibre/epoxy laminates show high stiffness and strength with low density and thus, advantageous specific mechanical properties. The drawback is that when FRPs are subjected to out-of-plane impact loads, interlaminar failure can cause a decrease of stiffness and strength.

There are many examples of dynamic loads on composite structures: solids of different masses (from hailstones, to big tools during maintenance operations) may impact on a CFRP laminate at different velocities (from dropping bodies to space debris). Studies of impact on composite laminates has been studied by many authors (see reviews of Abrate [1] and Cantwell et al. [2]) have focused on low velocity impact occurring during assembly or maintenance operations, but little attention has been given to ballistic impact. The first studies related to high velocity examined the energy absorption during impact and used analytical models based on energy balances to predict the residual velocity and damage extension on the laminate [3-4]. Other studies adopted a different point of view: Sun and Potti [5] proposed a model of two-noded ring element to predict the displacement of a laminate when subjected to impact loars. Some experimental work has been published: Kim et al. [6] studied the impact of ice spheres at high velocity on CFRP to evaluate the effect of hailstones on aircraft structures. Will et al. [7] performed high velocity inpact tests on CFRP-wound tubes to detect the response of pipes and vessels against this kind of load. Few of the numerical simulations of impacts on composite laminates have focused on the ballistic range (see Chen et al. [8] who simulated high velocity inpacts on CFRP laminates using a Smoothed Particle Hydrodymamics code). 


\section{TESTED MATERIAL AND PROJECTILE}

The laminate was provided by SACESA (Spain) from woven $A S 4 / 3552$ prepegs manufactured by HEXCEL, with a volumetric fibre content of $60 \%$. The stacking sequence was $[0]_{10}$, with a total thickness of $2.2 \mathrm{~mm}$. This material is widely used in the aeronautical and aerospace industries for panels subjected to torsion or to shear stresses. The elastic and strength properties are given in Table 1. The specimen size was $80 \times 80 \mathrm{~mm}^{2}$.

\begin{tabular}{|c|c|}
\hline Property & value \\
\hline$E_{1}=E_{2}[G P a]$ & 68.5 \\
$E_{3}[G P a]$ & 9.1 \\
$G_{12}[G P a]$ & 5 \\
$G_{13}=G_{23}[G P a]$ & 3.7 \\
$\nu_{12}$ & 0.22 \\
$\nu_{13}=\nu_{23}$ & 0.39 \\
$X_{T}[M P a]$ & 795 \\
$S_{f}[M P a]$ & 120 \\
$Z_{r}[M P a]$ & 74 \\
$S_{23}[M P a]$ & 64 \\
\hline
\end{tabular}

Table 1: Material properties.

For the impact tests we used a tempered steel projectile of $1.73 \mathrm{~g}$ mass, of a spherical shape to avoid scattered results due to changes in the yaw angle. The projectile material was hard enough to behave elastically during impact, so all the damage was located in the composite laminate.

\section{IMPACT EXPERIMENTS}

A SABRE gas gun was used to laumch the spherical projectiles. It uses helium gas bottle at a pressure of 200 bar to impel the fragment at velocities up to $550 \mathrm{~m} / \mathrm{s}$. This experimental device has two photoelectric cells that detect the projectile pass, from which the impact velocity is obtained. At the end of the gallery, the projectile reaches an armored box $\left(1 \times 1 \times 1 \mathrm{~m}^{3}\right)$ where the specimen is placed.

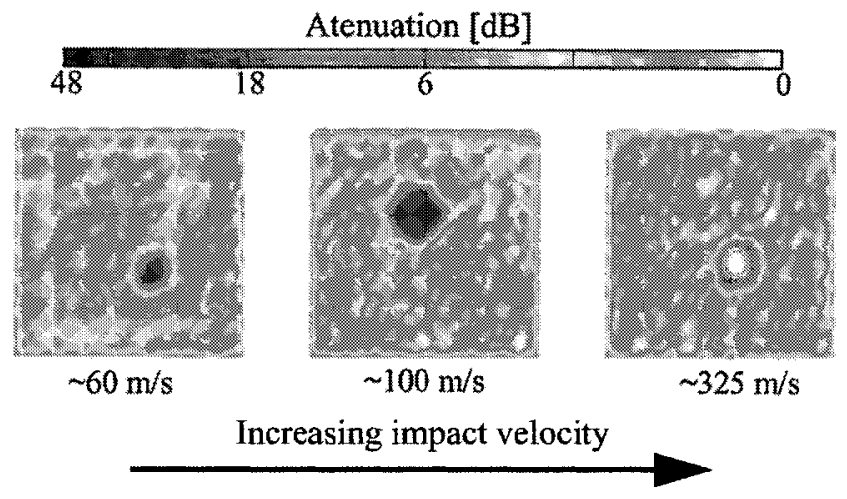

Figure 1: C-Scan images at different impact velocities. 
Tests were made at velocities between 60 and $550 \mathrm{~m} / \mathrm{s}$. After the test, the laminates were inspected with a C-Scan and the total damage extension was measured from the resulting images. Figure 1 shows the damage contours in specimens impacted at three different velocities. The first two were not perforated; the third has a small white area that corresponds to the hole made by the projectile in a perforation case (white means no attenuation of the ultrasonic signal). The CScan images were processed with MATLAB to measure the damage area. The pixels with signal attenuation over $4 d B$ were considered as representative of damaged material.

\section{NUMERICAL SIMULATIONS}

The numerical simulation, using the commercial finite element code ABAQUS [9], admits user subroutines in FORTRAN. To describe the mechanical behaviour of each ply of the laminate, an elastic matrix corresponding to an orthotropic material was adopted, as well as a failure model based in that proposed by Hou et al. [10]. As an extension of the Chang-Chang [11] failure model, Hou et al. considered four different types of damage (fiber failure, matrix cracking, matrix crushing and delamination), each associated to a parameter. When its value equals one, the ply loses stiffness in certain directions. The material considered in this work is woven, so the model was slightly modified to rate the fibers in two directions. Fiber failure (figure 2(a)) must extend in both in-plane directions:

$$
\begin{aligned}
& d_{f 1}=\left(\frac{\sigma_{11}}{X_{T}}\right)^{2}+\left(\frac{\sigma_{12}^{2}+\sigma_{13}^{2}}{S_{f}^{2}}\right) \geq 1 \\
& d_{f 2}=\left(\frac{\sigma_{22}}{X_{T}}\right)^{2}+\left(\frac{\sigma_{12}^{2}+\sigma_{23}^{2}}{S_{f}^{2}}\right) \geq 1
\end{aligned}
$$

where the constants $X_{T}$ and $S_{f}$ are the fiber strengths. On fiber failure, all the components of the elastic matrix are set to zero, so the stiffness of the material at the integration point is null.

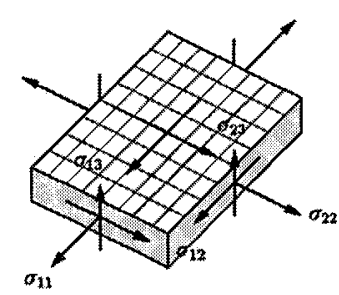

(a) Fiber failure

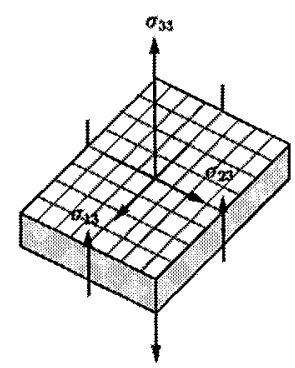

(b) Delamination

Figure 2: Stresses involved in the failure models.

The delamination failure criteria (figure $2(b)$ ) remain the same:

$$
d_{d}=\left(\frac{\sigma_{33}}{Z_{r}}\right)^{2}+\left(\frac{\sigma_{23}}{S_{23}}\right)^{2}+\left(\frac{\sigma_{31}}{S_{23}}\right)^{2} \geq 1 \quad \text { with } \sigma_{33} \geq 0
$$


in which $Z_{r}$ and $S_{23}$ are theply strengths. When $d_{d}=0, \sigma_{33}, \sigma_{13}$ and $\sigma_{23}$ are set to zero. Since the interlaminar surface is the weakest one in a woven laminate, delamination failure has to be considered. For matrix cracking and matrix crushing, $\sigma_{2}$ is the determinant stress in the Hou et al. [10] failure model. These two failure types were not considered in this work, since in the woven ply direction 2 is also reinforced. When $d_{f}$ or $d_{d}$ equals one at the integration points of an element, it distorts rapidly, so an element removal criteria was defined. At each time increment, the longitudinal strain in each direction of the ply axis is evaluated; if one of them reaches an ultimate value (see table 2), the element is removed from the mesh.

\begin{tabular}{ccc}
\hline$\varepsilon_{1}^{\text {ultimate }}(\%)$ & $\varepsilon_{2}^{\text {ultimate }}(\%)$ & $\varepsilon_{3}^{\text {ultimate }}(\%)$ \\
\hline 1.6 & 1.6 & 2.1 \\
\hline
\end{tabular}

Table 2: Ultimate strain values.

For the laminate, 116710 three dimensional 8-node reduced integration elements were used. The mesh is refined in the impact zone to simulate accurately the induced damage. The projectile was modelled using 4-node shell elements, with rigid behavior. Figure 3 shows the whole mesh and a zoom of the contact zone.

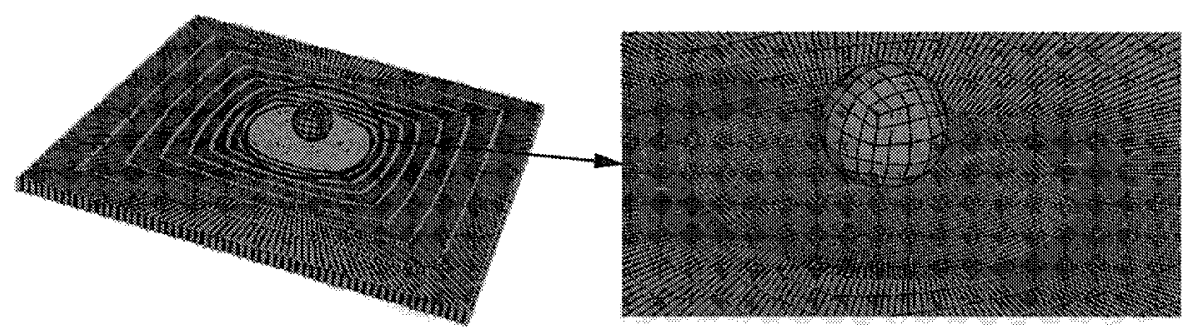

Figure 3: Mesh used in the numerical simulations.

\section{RESULTS}

Figure 4 shows an image of the deformed laminate mesh obtained by simulation and a photograph of the rear face of an impacted specimen. Both images correspond to a non-perforating impact. The same rhombus-shaped failure was observed, with four cracks starting from the rhombus vertices. This type breakage was observed by other investigators of high-speed impact on woven FRPs [6].

The simulation of the impact tests allowed a measurement of the predicted damage extension in the laminate. The damaged -and hence removed-elements were projected on to the undeformed mesh and its area calculated with MATLAB. These results are compared in figure 5(a) with the C-Scan measurements of the tested specimens. Experimental and predicted values show the same trend, reaching a maximum close to the ballistic limit $(\approx 100 \mathrm{~m} / \mathrm{s})$. Below this limit, damage extension increases with impact velocity whereas above the limit the damage decreases reaching an asymptotic value slightly greater than the area of the projectile cross section.

The residual velocity of the projectile predicted by the numerical model was compared with the results of a simple analytical model developed by Cantwell et al. $[3,4]$, based on the calculation of 

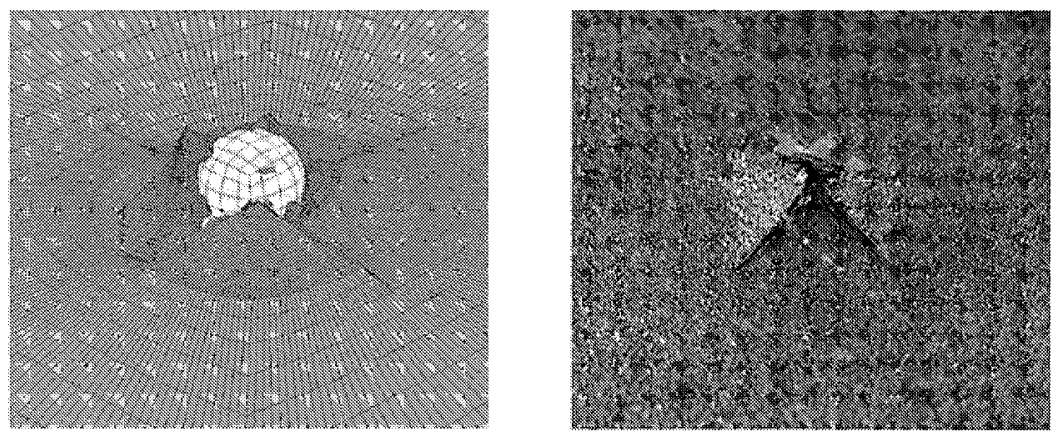

Figure 4: Comparison between numerical simulation and real impacted plate at $120 \mathrm{~m} / \mathrm{s}$.

the energy dissipated by damage in the composite plate $E_{a b s}$. In this range of velocities, $E_{a b s}$ may be consider constant and its value is determined by:

$$
E_{a b s}=[\sqrt{2} \pi t(t+2 r)] \cdot E_{s h e a r}
$$

where $t$ is the thickness of the plate, $r$ is the radius of the projectile, and $E_{\text {shear }}$ is the energy per unit of area to shear out the composite plug. Substituting in (4) the values of the considered laminate, $E_{a b s}$ is roughly $4.7 \mathrm{~J}$. Then, the expression used to calculate the residual velocity $v_{r}$ is

$$
v_{r}=\sqrt{\frac{\frac{1}{2} m v_{i}^{2}-E_{a b s}}{\frac{1}{2} m}}
$$

$v_{i}$ being the initial velocity and $m$ the projectile mass. Figure $5(\mathrm{~b})$ shows the residual velocities obtained with the numerical and the analytical model. Similar values were found in both analyses, although the analytical results overestimate the penetrating ability of the projectile. This could be due to the absence of an inertial term - plug acceleration - in $E_{a b s}$.

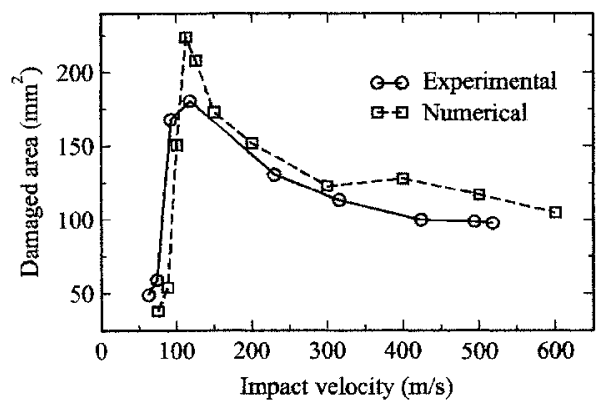

(a)

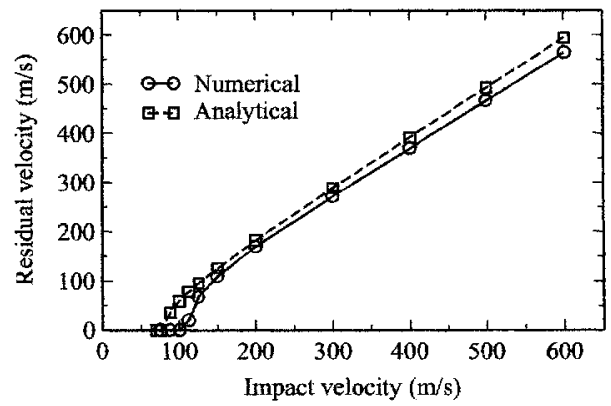

(b)

Figure 5: (a) damaged area vs impact velocity; (b) residual velocity vs impact velocity 


\section{CONCLUSIONS}

In the study of high-speed impact on carbon fiber/epoxy woven composites, C-Scan inspection of the tested laminates showed a peak in the damage extension at the ballistic limit velocity. Accurate predictions of daunage in the laminate were achieved by using an explicit finite element code. The failure model implemented in this code was based on that proposed by Hou et al. [10] and modified to consider reinforcement in two in-plane directions. The overall failure of the laminate predicted by the numerical code was coincident with that observed in the impacted specimens. The projectile residual velocity calculated with the finite element model were also close to that of the simplified model proposed by Cantwell and Morton [3-4].

\section{Acknowledgements}

The authors are indebted to the Comisión Interministerial de Ciencia y Tecnología of Spain for financial support of this work (Project MAT98-0273). They also thank EADS-CASA for assistance in C-Scan measurements.

\section{References}

[1] Abrate S., Impact on laminated composite materials, Appl. Mech. Rev. 44, no. 8, (1991) pp. $155-190$.

[2] Cantwell W.J., Morton J., The impact resistance of composite materials - a review, Composites 22, no. 5, (1991) pp. 347-362.

[3] Cantwell W.J., Morton J., The ballistic perforation of CFRP, Proc. Conf. Impact Polym. Mat. 17, (1985) pp. 1-6.

[4] Cantwell W.J., Morton J., Impact Perforation of Fibre Reinforced Plastic, Composites Science and Technology 38, (1989) pp. 119-141.

[5] Sun C. T., Potti S. V., A simple model to predict residual velocities of thick composite laminates subjected to high velocity impact, Int. J. Impact Engng. 18, no, 3, (1995) pp. 339-353.

[6] Kim H., Welch D. A., Kedward K. T., Experimental investigation of high velocity ice impacts on woven carbon/epoxy composite panels, Composites: Part A 34, (2003) pp. 25-41.

[7] Will M. A., Franz T., Nurick G. N., The effect of laminate stacking sequence of CFRP filament wound tubes subjected to projectile impact, Composites Structures 58, (2002) pp. 259-270.

[8] Chen J. K., Allahdadi F. A., Carney T. C., High-velocity impact of graphite/epoxy composite laminates, Composite Science and Technology 57, (1997) pp. 1369-1379.

[9] ABAQUS/Explicit User's Manual, Version 6.2, Hibbit, Karlsson and Sorensen, Inc (2002).

[10] Hou J. P., Petrinic N., Ruiz C., Hallet S. R., Prediction of impact damage in composite plates, Composite Science and Technology 60, (2000) pp. 273-281.

[11] Chang F., Chang K. A., A progressive damage model for laminated composites containing stress concentrations, Journal of Composite Materials 21, (1987) pp. 834-855. 